\title{
BECKETT E A LÍNGUA DOS OUTROS — QUE OUTROS?
}

\section{Helena Martins}

Este texto busca na escrita de Samuel Beckett uma ocasião para pensar a tradução. A estratégia mais imediatamente insinuada seria talvez investir na avenida aberta pelos importantes estudos dedicados às práticas do Beckett autotradutor, práticas que vêm despertando interesse já há bastante tempo, pelo menos desde o hoje clássico artigo de Ruby Cohn, "Samuel Beckett self-translator”, publicado em 1961. Desde então, muitos dos trabalhos debruçados sobre os procedimentos beckettianos de autotradução louvaram a facilidade extraordinária com que, no comércio entre o francês e o inglês, o autor soube reproduzir efeitos particularíssimos e aparentemente ultrarrecalcitrantes que tinha alcançado em seus originais: jogos de palavras, rimas, paranomásias, gírias, duplossentidos etc. Outros tantos estudos preferiram, em direção oposta, deter-se nas singulares e eloqüentes discrepâncias entre os textos de origem e os traduzidos, destacando, por exemplo, acentuadas desproporções quanto à presença da obscenidade e do humor; enigmáticas "correções", supressões e acréscimos de frases e passagens inteiras; marcantes diferenças de tom e de registro, e assim por diante. ${ }^{1}$

Não há dúvida de que o jogo delicado e ambivalente que marca as relações de reciprocidade entre os textos originais e traduzidos de Beckett convida ainda hoje à reflexão - e o tema não deixará de comparecer neste trabalho. Mas a ênfase aqui será outra, tomarei um caminho um pouco menos frequentado: desejo esboçar uma reflexão beckettiana sobre a questão da alteridade, no que esta tem de fulcral para os estudos da tradução. Mais especificamente, este texto busca recolher elementos para pensar a relação entre tradução e alteridade na forma singular com que a escrita de Beckett nos permite reconhecer "a língua do outro" (dos outros).

Se a aspiração é essa, um ponto que reclama atenção instantânea é naturalmente o interesse especial de Beckett por uma língua outra — o francês —, sua resoluta disposição de escrever num idioma estrangeiro, pelo menos desde 1937.

\footnotetext{
${ }^{1}$ Parecem distribuir-se entre essas duas ênfases, por exemplo, as abordagens encontradas em Coe (1983), Connor (1989), Friedman et al. (1989), McGuire (1990), Mooney (2002), Cerrato (2007).
} 
Ao que parece, ele abraçou com afeto equiparável a língua francesa e a França: em setembro de 1939, Beckett visitava sua mãe na Irlanda, quando Hitler invadiu a Polônia; em vez de permanecer em segurança na terra natal, retorna imediatamente a Paris, declarando que preferia a França em guerra à Irlanda em paz. Em outra ocasião, perguntam-lhe: "Vous êtes anglais, Monsieur Beckett"? "Au contraire", foi a sua cômicoenigmática resposta (Ackerley e Gontarski, 2004: 206) — uma resposta irlandesa? francesa? estrangeira? uma resposta que logra impugnar a própria retórica nacionalista insinuada na pergunta? Essas não são, creio, meras anedotas biográficas; em outras circunstâncias mereceriam uma atenção detida.

Interesso-me mais aqui, no entanto, por considerar as razões com que Beckett justificou a adoção do francês em sua escrita: "é porque em francês posso escrever sem estilo", ele diz em certa ocasião a Niklaus Gessner². E a Charles Juliet explica em outro momento que, sendo "ainda uma língua nova" para ele, o francês preservava "uma aura do desconhecido" que lhe permitia "escapar aos hábitos inerentes à sua língua nativa": segundo Ackerley e Gontarski, isso corresponderia a uma necessidade de escapar ao virtuosismo formal da literatura modernista, substituir sua literariedade por uma literalidade (2004: 206). Laura Cerrato sugere, por sua vez, que a adoção do francês corresponde ao desejo de Beckett de se despojar da espessura retórica contrabandeada nos usos mais cotidianos de sua língua, de se livrar dos tropos já inaudíveis no inglês que alcançava seu habituado ouvido irlandês (2007: 31). Adotando uma língua desacostumada, Beckett estaria assim reagindo contra a mitologia branca infundida no idioma (Derrida 1991), de modo a ter mais chances de se aproximar do ideal (reconhecidamente inatingível) da escrita direta.

Podemos então pensar na adoção do francês como um dos meios de que Beckett se valeu para realizar algo que se tem por vezes reconhecido como uma das marcas distintivas de sua escrita: um apotropismo generalizado, um decidido afastamento de toda linguagem figurativa (v. Wolosky 1989, 1991).

Já se reconheceu também por outro lado que essa resoluta fuga das figuras convive em tensão com uma irrefreável e paradoxal propensão à provocação figurativa: se é

\footnotetext{
2 Citado em Coe (1983: 37). São minhas todas as traduções de textos citados a partir de originais em língua estrangeira.
} 
verdade que Beckett frustra a interpretação e o conforto hermenêutico, também é verdade que esse interdito se faz acompanhar em seus textos de um sistemático convite ao interpretar, de uma quase ininterrupta incitação simbólica. Trata-se com efeito de uma desconcertante e endêmica estratégia, presente em múltiplos planos da escrita beckettiana: manifesta-se, por exemplo, na peculiar sugestividade onomástica de seus textos, no constante evocar de metáforas gastas e frases feitas, na insistência misteriosa sobre certos objetos, na perturbadora trama alusiva, nas quase irreprimíveis evocações alegóricas. $^{3}$

Julgo oportuno ilustrar aqui essa estratégia com a célebre frase final de Watt, imperativo em que se tem reconhecido amiúde a própria expressão metonímica do vetor antifigurativo da escrita beckettiana: "No symbols where none intended" (p. 379).

Não interprete! - eis o que parecem ordenar as palavras escritas ao final desse livro, que no entanto vem incitando desde então as mais variadas interpretações alegóricas: Watt seria uma alegoria da busca da verdade, ou do bem, ou do nada, ou do self, ou de Deus, ou do sentido, ou da falta de sentido, e assim por diante (Szafraniec, 2007: 74ff). Que nenhuma dessas alternativas ofereça qualquer conforto simbólico não impediu que tenham sido tão amiúde aventadas: simultaneamente às suas declaradas exortações anti-hermenêuticas, a escrita de Beckett parece fazer a toda hora o convite oposto: Interprete!

Para percebermos a convivência paradoxal desses imperativos no hoje célebre adágio beckettiano, não é sequer preciso lê-lo na contraluz das suas adjacências no romance. Mesmo avulsa, a frase já dá a ver a forma singular com que o autor nos recomenda adesão à letra ao mesmo tempo em que nos provoca de modo bastante explícito a "ultrapassá-la". Pois trata-se de um dito que surge precisamente do desacostumar de outras frases, frases de história mais antiga e efeito mais automático, cujo parentesco vocabular e rítmico dificilmente se deixa passar despercebido: ao ler "no symbols where none intended", é difícil não ouvir também o eco de fórmulas como (take) no offence where none is intended, no offence intended, none taken, no offence taken, none meant, e assim por diante.

\footnotetext{
${ }^{3}$ Exploraram esse gesto paradoxal em Beckett, por exemplo, Barry (1978), Nykrog (1984), Rabinowitz (1985, 1995), Perloff (1996, pp. 115-143), Martins (2009).
} 
Muito se insinua nessa convivência entre o dizer modificado e suas contrapartes mais habituadas: intriga de saída a sobreposição entre a cena expressivo-reflexiva da leitura - atividade estereotipicamente solitária — e a cena ético-performativa da ofensa evocada e negada na economia tensa dos atos de fala cotidianos. Intriga também, com efeito, perceber que o simbólico é negado em frase que rememora uma fórmula típica de situações nas quais negar já é também afirmar: quem diz no offence ("sem querer ofender...") já dá em geral o testemunho da ofensa potencial, já acomoda de certa forma alguma interrogação quanto à "pureza" da própria intenção - já faz, por assim dizer, pairar sobre o contexto, mais carregada do que de hábito, a nuvem perene do descompasso entre intenção e ação. Tudo isso intriga de fato, mas neste momento gostaria apenas de pontuar o modo singular como Beckett reenvia quase compulsoriamente a outras frases a própria frase que interdita esse reenvio, dando-lhe ares proverbiais, de fórmula gasta e condensada.

Igualmente relevante para este texto é, claro, considerar a tradução que receberam essas palavras finais de Watt na versão francesa do livro (1968), traduzido por Agnès e Ludovic Janvier, em colaboração com o próprio Beckett: "honni soit qui symboles y voit" (literalmente, "envergonhem-se os que nisto veem símbolos").

Aqui a estratégia se complexifica, multiplica-se: como acontece em inglês, a frase em francês recomenda paradoxalmente a atinência à letra ao mesmo tempo em que, por assim dizer, nos expulsa para além dela; pois, também nesse caso, o enunciado evoca a frase acostumada que vem perturbar, o célebre honni soit qui mal y pense ("envergonhem-se os que nisto veem malícia”).

Vale a pena relembrar brevemente aqui a lenda sobre a origem desse dito, até hoje o lema da Ordem da Jarreteira, comenda britânica criada pelo rei Eduardo III no tempo das cruzadas. Por ocasião de um baile, a condessa de Salisbury, dama da corte do referido rei, viu a certa altura escorregar-lhe da perna a sua jarreteira; ao percebê-lo, o rei baixou-se rapidamente para apanhar e devolver a tal liga à dama, tendo isso motivado olhares, risos e murmúrios por parte dos presentes, o que teria despertado a ira do rei, levando-o então a exclamar: Honni soit qui mal y pense! Para deixar claro que seu gesto era despojado de quaisquer conotações espúrias (isto é, de qualquer simbolismo sexual), o rei teria amarrado a liga à própria perna e feito dela a insígnia que os membros da referida ordem 
militar vestem até hoje em cerimônias especiais: uma jarreteira azul com o dito ali inscrito em letras douradas.

Como já observou Mary Lydon, salta aos olhos o fato paradoxal de que é "por meio de um gesto simbólico deliberado que o rei pretende deter a interpretação culposa e incontrolavelmente simbólica a que o incidente se presta de início" - fica claro que "no próprio ato de repúdio ao símbolo, Eduardo dele se faz refém” (1988: 157). A frase de Watt, em francês, remete então a um dito acostumado, que por sua vez convoca toda uma história paradigmática do próprio curto-circuito simbólico implicado no desconcertante imperativo anti-hermenêutico de Beckett.

Em inglês e em francês, o enunciado em foco ilustra então uma estirpe particularíssima de apotropismo, o movimento de uma prosa em que as figuras são evitadas com a mesma ênfase e sistematicidade com que são convidadas. Vista sob esse ângulo, a adoção do francês serviria não apenas ao imperativo da escrita direta, sem estilo, sem símbolos, mas sobretudo à facilitação e ao maior controle dessa intrigante estratégia de provocar e frustrar as nossas aparentemente irreprimíveis expectativas simbólicas. Cabe então perguntar: se é para frustrar, por que provocar?

Numa interpretação frequente, as provocações simbólicas de Beckett são reconhecidas como testemunhos da falência da linguagem: com essas provocações, supõe-se, Beckett estaria sublinhando a ausência do hors-text, a natureza em última instância autorreferencial da linguagem. Sob esse ponto de vista, que de tão conhecido hoje já ganha ares quase dialetais (pelo menos nos círculos acadêmicos), o literal não é mais que figura disfarçada, e a figura só leva a outras figuras: ao simultaneamente provocar e interceptar a interpretação simbólica, ao mostrar que sua onipresença é proporcional à sua impossibilidade última, Beckett estaria impugnando a confiança na linguagem como sistema objetivo de representação, como instrumento eficiente de referência ao mundo exterior ou interior. Este seria, para muitos, "o Beckett pósestruturalista": com esse Beckett, "significantes obliteram os significados, e a linguagem se torna mais autorreferente e menos externa", num mundo em que "modelos, códigos, 
mitos e palavras flutuam à deriva, tendo perdido contato ou rompido com suas "origens"" (Ackerley e Gontarski, 2004: xiv-v). ${ }^{4}$

No que tange ao assunto que mais de perto nos concerne aqui, note-se que muitos viram nas flagrantes discrepâncias entre os textos originais e traduzidos de Beckett uma marca a mais desse vetor pós-estruturalista. Nas palavras de Steven Connor (1989: 127), por exemplo, as traduções beckettianas "dramatizam a percepção de que a linguagem não é senão ficção, tradução sem original, espaço em que se anulam tanto as identidades dos textos quanto as suas relações de prioridade"; disso resultaria, para o autor, a "perda de uma obra única e definitiva capaz de controlar e orientar o jogo entre as versões primárias e secundárias". Ignorando a sensação de que o fraseado de Connor se acomoda sem muito conforto sob o que reconheço como pós-estruturalismo, não há como negar que as autotraduções de Beckett parecem impor, no mínimo, que arranhemos com muitas aspas as adjacências das palavras "original" e "tradução". Em mais de uma ocasião, na colaboração com seus tradutores, o próprio Beckett sublinhou que não se tratava de traduzir, mas antes de "escrever o livro de novo em outra língua, isto é, de escrever um novo livro" (Patrick Bowles, comentando a sua parceria com Beckett na tradução de Molloy, citado em Knowlson e Knowlson 2006: 109).

Parece-me de resto óbvio que o achado literário (e tradutório) de Beckett pode ser associado à perturbação da ideia de que há um télos racional na linguagem, e de que sua vocação é meramente instrumental. É claro que Beckett, como tantos outros artistas e filósofos do nosso tempo, investe contra a crença tácita e arraigada em uma "providência pré-discursiva" que "dispõe o mundo a nosso favor", tornando legível a sua face e reservando à linguagem o lugar honrado mas inócuo da representação (Foucault, 1996: 53). Ilustra a força desse investimento subversivo a conhecidíssima passagem de $O$ inominável de onde sai o título deste artigo:

[...] sou de palavras, sou feito de palavras, das palavras dos outros, que outros, e o lugar também, o ar também, as paredes, o chão, o teto, o universo está todo aqui, comigo, sou o ar, as paredes, o emparedado, tudo cede, tudo se abre, anda à deriva, recua, flocos, sou estes flocos todos, que se cruzam, se unem, se separam [...] essa poeira de verbo, sem fundo onde pousar, sem um céu para se dissipar [...] (p. 148,

\footnotetext{
${ }^{4}$ Leituras semelhantes encontraremos, por exemplo, em Barry (1978), Ben-Zvi (1980), Magarit (2003), Cerrato (2007).
} 
grifo meu)

Não há dúvida de que neste e em muitos outros momentos de sua escrita Beckett perturba a lógica quase compulsória que duplica a linguagem em superfície heteróclita sobre fundo homogêneo - não há dúvida de que ele enfatizou tanto a autonomia e a volatilidade da linguagem quanto o seu poder demiúrgico, sua capacidade de fabricar: o céu, o teto, as paredes, a mim mesmo, o outro.

Essa ênfase dupla permitiu discernir em Beckett uma "arte aporética", uma poética do impasse. São conhecidas e muitas as instâncias desse tom na escrita do autor: “não posso continuar, vou continuar" (O inominável); “o fim está no começo e no entanto continua-se" (Fim de partida); "nada a expressar, junto à obrigação de expressar" (Três diálogos com G. Duthuit).

Somos afinal "essa poeira de verbo sem fundo onde pousar, sem céu para se dissipar": as palavras são a um tempo demiúrgicas e infranqueáveis, fazem o mundo, a mim e o outro, mas cedem, andam à deriva, não conduzem ao mundo, a mim ou ao outro. No caso deste texto, a região particular do embaraço que exige atenção redobrada é, claro, a de sermos feitos das palavras dos outros - mas que outros?

São de fato muitas as ocasiões em que Beckett sublinha esse aspecto particular do impasse. Na hipnose ritmada e sombria da peça-poema Rockaby, por exemplo, ele o faz valendo-se com frequência da estratégia de assalto às formas cristalizadas de expressão, aqui já apontada: desacostuma, por exemplo, a fórmula trivial "ela disse a si mesma", com a sequência provocadora "a quem mais". "Eu conhecia mal as mulheres, naquela época", diz o narrador de Primeiro amor (PA), quebrando de forma semelhante, na continuação, o horizonte que a frase prometeria habitualmente abrir: "Ainda as conheço mal, aliás. Os homens também. Os animais também. O que conheço menos mal são as minhas dores" (p. 6). A evocação do solipsismo tem sido muitas vezes reconhecida na obra de Beckett (v. Marculsecu, 1989) — de fato, comparece amiúde na escrita do autor o motivo do hiato entre o "eu" e "esse resíduo de futilidades peçonhentas que chamamos de não-eu, ou mesmo de mundo, por preguiça" (PA: 5). Claro está, por outro lado, que a identidade do "eu" não é de modo algum estável, não se oferece absolutamente como

\footnotetext{
5 “[...] till in the end/ the day came/ in the end came/ close of a long day/ when she said/ to herself/ whom elsel time she stopped [...]" (Rockaby, p. 462 e segs., grifo meu).
} 
objeto mais dócil de (re)conhecimento, conforme arremata o narrador de Primeiro amor: “Aliás, conheço mal também as minhas dores" (PA: 6). A crise da alteridade é também, como sempre, a crise de identidade. $\mathrm{O}$ experimento radical de $O$ inominável nos dá uma mostra notável da forma singular com que Beckett dá a ver a reciprocidade entre essas duas "crises": pois é, como disse certa vez M. Blanchot, "um experimento conduzido, uma experiência vivida, sob a ameaça do impessoal, a aproximação de uma voz neutra que grita por si, que invade quem a escuta, que não tem intimidade, que exclui toda intimidade" (1979 [1953]: 119). Nem o eu, nem o outro — somente "a voz" (v. Ackerley e Gontarski 2004: 607-618).

Isso parece, a princípio, nos devolver à possibilidade de reconhecer na escrita de Beckett uma direção pós-estruturalista, sobretudo se a tal direção se associa uma ênfase na autorreferencialidade da linguagem. Se somos feitos das palavras que não são afinal nem nossas, nem dos outros, isso se deveria à falência referencial da linguagem, à qual não restaria senão dobrar-se sobre si mesma. Toda identidade - e toda alteridade seria, sob esse hoje conhecidíssimo ângulo, nada mais do que efeito ilusório de linguagem. Do ponto de vista que nos concerne aqui mais de perto, isso repercutiria, como já se disse, numa aniquilação das relações tradicionais de prioridade entre "original" e "tradução", de vez que nenhum texto de origem seria jamais franqueado etc. etc.

Ainda assim, parece-me que as inflexões céticas e solipsistas do investimento beckettiano contra a visão essencialista de que a linguagem se deixa estabilizar por um centro de gravidade e é capaz de dizer um fora, embora possam sem dúvida ser associadas à sua tão falada "estética do fracasso" e à sua "literatura da despalavra", convivem com outras inflexões em que encontro espaço para talvez pensar diferentemente a questão da alteridade e sua relação com a tradução. Venho então tentando alcançá-las, buscando uma outra forma de reclamar o legado de Beckett.

Do ponto de vista que acabo de descrever, a percepção da falta de fundamento da linguagem coincidiria com a adoção de uma atitude de descrença ou, no mínimo, de guarda armada em relação às virtudes da tradução, sempre incapaz de honrar a sua vocação culturalmente reconhecida (e qual senão esta?): trazer para uma língua algo de outro, algo de outra língua, de outra cultura, de outro autor. Sob uma atmosfera de 
hipervigilância crítica, estaríamos, pois, a todo momento preparados para perceber a tradução, agora paradigma de toda a linguagem, sob o signo da falta: sendo em última instância ilusória toda experiência de compreensão, todo acesso ao mundo, ao outro, ao próprio self, estaríamos, por assim dizer, condenados a viver na falta de um mundo, de um outro, de um texto original.

Sem deixar de reconhecer a contundência desse vaticínio, de ouvir, digamos, a sua (exausta?) "verdade", tenho tentado escutar também com atenção passagens que, na escrita de Beckett, insinuam outras direções, reforçam outras possibilidades.

Ouçamos Beckett quando nos diz, por exemplo, em "Três diálogos com Georges Duthuit", as seguintes palavras, tão promissoras quanto difíceis: "há algo mais do que uma diferença de grau entre viver a escassez, escassez do mundo, escassez de si (self), e encontrar-se completamente sem essas estimadas comodidades. Um é um embaraço, o outro não" (p. 179, grifo meu; v. Martins 2009a). Uma condição alternativa parece ser aqui insinuada, esboça-se a possibilidade de um lugar que, sem depender de um fundamento para a linguagem e para a existência, não embaraça — promete deslocar de alguma forma o aparentemente irremovível signo da falta. Mas o que seria viver sem o mundo, em vez de viver a escassez do mundo? Como poderia isso não ser um embaraço?

Venho cortejando a seguinte possibilidade: uma maneira de explorar a força dessa passagem é encontrar na escrita de Beckett ocasião para enfraquecer a ênfase na suposta autorreferencialidade da linguagem, de modo que esta possa emergir de forma ainda mais radicalmente afastada do plano da referência, escapando até mesmo talvez à "maldição" da autorreferência (Martins 2009a, 2009b). Nos textos de Beckett encontro uma remota promessa de "conjurar" essa maldição, de enxergar ou viver a linguagem de uma outra forma. Isso significa tomar um ponto de vista potencialmente capaz de alterar de modo sutil a percepção da língua do outro, e portanto da tradução, afastando-as ambas, talvez, dos terrenos de escassez do solipsismo e do ceticismo.

Pois se dizemos coisas como "não temos acesso ao mundo"; "não há como chegar ao outro ou a mim mesmo"; "estamos presos na malha da linguagem"; "não há texto original" etc. etc. — não será isso exatamente o tipo de embaraço a que Beckett se referiu como "viver a escassez"? O cético ou o solipsista viveriam a escassez do mundo, do self — vale dizer também do outro — , pois, lamentando eternamente a impossibilidade de 
alcançá-los, ainda os tomariam, por assim dizer, como balizas, ainda estariam presos a essas suprainstâncias negadas por uma espécie de nostalgia.

Viver sem o mundo seria algo radicalmente distinto de viver a escassez do mundo, entre muitas outras coisas, porque imporia deter até mesmo a retórica da hipervigilância crítica que denuncia a todo momento a natureza supostamente ilusória de toda identidade e de toda alteridade; significaria reconhecer nessa retórica, ao lado de sua insidiosa "verdade", ainda uma ambição reducionista, ainda uma uniformidade alcançada "por decreto" - ainda, talvez, uma espécie de versão negativa da propensão metafísica à “igualação do não igual”, para usar a famosa e metonímica expressão de Nietzsche.

Ceticismo e solipsismo são, lembremos, filosofias gerais (não é possível conhecer, não temos acesso aos outros etc.). Mas o que encontramos em Beckett não é, lembremos ainda, filosofia geral, doutrina. Como ele mesmo se encarrega de esclarecer, em resposta a um entrevistador interessado em reconhecer influências filosóficas em sua obra: "eu não teria tido nenhuma razão para escrever meus romances se pudesse ter expressado seu assunto em termos filosóficos" [...] "Não sou um intelectual. Tudo que sou é sentimento" (1979 [1961]: 217). Reagindo a um outro entrevistador que lhe perguntara se, como os filósofos, desejava dizer a verdade, ele responde: "O que é mais verdadeiro do que qualquer outra coisa? Nadar é verdade, mas afundar também. [... P]ode-se falar apenas da bagunça [...] Pode-se falar apenas daquilo que se encontra à frente de nossos olhos e, agora, trata-se simplesmente de ver a bagunça” (1979: 219). E falar da bagunça é falar da bagunça da linguagem.

De um ponto de vista que se queira sensível à sua bagunça, a linguagem promete liberar-se da maldição da autorreferência, que parece condenar ao signo da falta toda identidade e toda alteridade. Pois concluir que, dada a sua incapacidade de se referir a um fora, a linguagem não cumpre afinal a sua função, restando-lhe apenas dobrar-se sobre si mesma, é ainda reduzir a bagunça da linguagem, é ainda reconhecer na referência a sua vocação única ou, pelo menos, a mais nobre.

Aceitar que a linguagem não tem "fora", que, nos termos especialmente aptos de Wittgenstein, "não é contígua ao que quer que seja" (Lectures 1930-32: 112), não implica, em suma, em condená-la à autorreferência. Se escutamos suficientemente bem o 
filósofo, e a meu ver também Beckett, a linguagem pode ser entrevista, em vez disso, como forma de vida — irredutível e inexplicável.

"Se só houvesse escuridão", Beckett nos diz, "tudo estaria claro", acrescentando que "é porque não há somente escuridão, mas também luz, que nossa situação se torna inexplicável" (1979: 220). A clareza do breu total: a paz explicativa prometida no oximoro - a paz escura da indistinção absoluta de tudo - tampouco nos é franqueada. Beckett parece aqui insistir na insistência das distinções, na luz inexplicável — porque sem fonte - das identidades e das diferenças. A escrita beckettiana nos convida, por assim dizer, a aceitar o inexplicável pelo que é - a conter até mesmo, talvez, o impulso reducionista que decreta, por assim dizer, o império da ilusão.

Pois inexplicável não é, sem dúvida, o mesmo que ilusório.

Se a linguagem é reconhecida de maneira radical como forma de vida, é preciso reconhecer também que as identidades que nela e com ela se forjam não são propriamente ilusórias - pois, desse ponto de vista, não haveria qualquer parâmetro externo com que aferir o suposto logro. Renunciar de forma radical à compreensão da linguagem como sistema de representação seria, por esse ângulo, renunciar também a percebê-la como sistema falido de representação.

E, no entanto, Beckett não se cansa de sublinhar em seus textos algo que, em sua célebre "Carta alemã", resumiu com a expressão "a desgraça da linguagem". Como compreender o que seja essa "desgraça" sob o ângulo sutilmente deslocado que venho tentando alcançar aqui? Uma possibilidade: a desgraça da linguagem não seria tanto a sua incapacidade de dizer um fora, mas sobretudo a sua propensão aparentemente ineliminável a promover e reforçar a expectativa dessa capacidade. Em outras palavras, a maldição estaria na circunstância, pelo menos ocidental, de a linguagem manter com a cultura logocêntrica laços tão mutuamente constitutivos. O logocentrismo não é (apenas) uma teoria inadequada sobre a linguagem - em certa medida importante, forja-se nela, impõe-se ali, para repetir a expressão de Derrida, como mitologia branca. Sublinhando e mesmo radicalizando essa (desgraçada) mitologia - entre outras coisas com o seu singular e paradoxal apotropismo —, a escrita de Beckett promete de alguma forma subvertê-la. 
Como pensar, em suma, a "língua do outro" e a relação entre tradução e alteridade na esteira do que se discutiu acima? Dois caminhos se insinuaram, indico-os agora em retomada admitidamente inconclusiva.

O primeiro teria a ver com a possibilidade (remota) de deslocar o signo da falta, de enfraquecer a retórica da escassez implicada na percepção da linguagem como acontecimento inevitavelmente autorreferente: do ponto de vista que busquei esboçar aqui, a língua do outro e portanto a tradução e o texto original são inexplicáveis, mas não ilusórios; não se deixam reduzir, mas tampouco faltam. Ao contrário, a língua do outro, a tradução, o original insistem inexplicavelmente em distinguir-se, ainda que não se ofereçam jamais da forma superlativa suposta e reforçada tanto na cultura logocêntrica quanto em certas versões de antilogocentrismo. É atento a essa insistência, talvez, que Beckett se volta com tanto interesse para uma outra língua, o francês - o que nos traz ao segundo caminho oferecido em sua escrita para pensar as questões que aqui nos animaram.

No consórcio entre o francês e o inglês, os experimentos radicais de Beckett logram, por assim dizer, soprar as brumas reducionistas que envolvem a linguagem sob o signo da referência - ou de sua falta - , permitindo-nos entrevê-la como forma de vida irredutível, como acontecimento no qual as palavras fazem, mais do que dizem. Para voltar ao exemplo oportuno de que me vali aqui, reconhecendo-se o que faz a frase "no symbols where none intended", fica difícil não considerar excelentíssima a sua surpreendente tradução para o francês como "honni soit qui symboles y voit".

A disposição de Beckett para habitar a língua do outro, a língua hostil e desacostumada, aliada à sua disposição de retornar, amiúde por tradução, à sua própria língua, pode ser lida como um meio pelo qual o autor busca restituir à linguagem a sua mal disfarçada estranheza, abalar performativamente as expectativas reducionistas e uniformizantes que nela mesma se forjam e se reforçam. A ocasião da tradução, isso não é novidade, é ocasião propícia a estranhar-se a própria língua, confrontar a cultura consigo mesma. Na escrita de Beckett em particular, a tradução parece ser não apenas um momento para confrontar a linguagem com sua própria desgraça, mas também, talvez, para reconhecer nessa desgraça os contornos de uma cultura, uma cultura da escassez - 
uma cultura entre outras possíveis? Qualquer que seja o caso, parece-me claro que a tradução, a busca da língua do outro, confunde-se em Beckett com a busca de uma outra relação com a linguagem, uma relação sensível à sua claro-escura bagunça.

\section{Referências bibliográficas:}

ACKERLEY, Chris J. \& GONTARSKI, Stanley E. (2004) The Grove companion to Samuel Beckett. New York: Grove Press.

ANDRADE, Fábio de Souza. Samuel Beckett: o silêncio possível. São Paulo: Ateliê Editorial.

BARRY, David. A. (1978) "Beckett: l'entropie du langage et de l'homme". The French Review 51 (6), 853-863.

BECKETT, Samuel (2006 [datas variadas]) Samuel Beckett: The Grove centenary edition. Paul Auster (org.) vols I (Novels), II (Novels), III (Dramatic Works), IV (Poems / Short Fiction / Criticism), New York: Grove Press. (1979 [1961]) "Interviews with Samuel Beckett (1961)”. Lawrence Graver e Raymond Federman (orgs.) Samuel Beckett: the critical heritage. London: Routledge \& Kegan Paul. (2001 [1937]) "Carta de Samuel Beckett a Axel Kaun, a 'Carta alemã' de 1937”. Trad. de Fábio de Souza Andrade. Samuel Beckett: o silêncio possível. São Paulo: Ateliê Editorial. (2002 [1957]) Fim de partida. Trad. de Fábio de Souza Andrade. São Paulo: Cosac Naify. (2002 [1953]) O inominável. Trad. de Maria Jorge Vilar de Figueiredo. Lisboa: Assírio \& Alvim. (2004 [1970]) Primeiro amor. Trad. de Célia Euvaldo. São Paulo: Cosac Naify. (2001 [1965]) "Três diálogos com Georges Duthuit". Trad. de Fábio de Souza Andrade. Samuel Beckett: o silêncio possível. São Paulo: Ateliê Editorial.

BEN-ZVI, Linda (1980) "Samuel Beckett, Fritz Mauthner, and the limits of language". PMLA 95 (2), 183-200.

BLANCHOT, Maurice (1979 [1953]) “The unnamable". Translated by Richard Roward. Lawrence Graver \& Raymond Federman (orgs.) Samuel Beckett: The Critical Heritage. London: Routledge \& Kegan Paul.

CERRATO, Laura (2007) Beckett: el primer siglo. Buenos Aires: Ediciones Colihue.

COE, Richard N. (1983) "Beckett's English". Morris Beja, Stanley E. Gontarski, Pierre A. G. Astier (orgs.) Samuel Beckett-humanistic perspectives. Columbus: Ohio State University Press.

CONNOR, Steven (1989) “Traduttore, traditore': Samuel Beckett's translation of Mercier et Camier". Journal of Beckett Studies 11 \& 12, 27-46.

DERRIDA, Jacques (1991 [1971]) “A mitologia branca”. Margens da filosofia. Trad. de Joaquim Torres Costa e Antônio M. Magalhães. Campinas: Papirus.

FOUCAULT, Michel (1996 [1970]) A ordem do discurso. Trad. de Laura Fraga de Almeida Sampaio. São Paulo: Loyola. 
FRIEDMAN, Alan Warren; ROSSMAN, Charles \& SHERZER, Dina (orgs.) (1987) Beckett translating/translating Beckett. University Park: Pennsylvania State UP, 1987.

KNOWLSON, Elizabeth e KNOWLSON, James (orgs.) (2006) Remembering Beckett. London: Bloomsbury.

LYDON, Mary (1988) "Skirting the issue: Mallarmé, Proust, and symbolism". Yale French Studies 74, 157-181.

MAGARIT, Lucas (2003) Samuel Beckett: las huelas en el vacío. Madrid, Buenos Aires: Editorial La Avispa S. L. \& Atuel.

MARCULESCU, Ileana (1989) "Beckett and the temptation of solipsism: 'Esse est aut percipere aut percipi"”. Journal of Beckett Studies (special double issue) 11 \& 12, 53-64.

MARTINS, Helena (2009a) "O chapéu de Beckett”. Gragoatá 26, 135-154.

(2009b) "A linguagem que não é razoável (ou irrazoável): breve diálogo entre Wittgenstein, Beckett e Rosa”. Cuadernos de Intercambio Rosario-Río de Janeiro 1, 63-71.

McGUIRE, James (1990) "Beckett, the translator, and the metapoem". World Literature Today 64 (2), 258-263.

MOONEY, Sinead (2002) “"an Atropos all in black' Or, Ill seen worse translated: Beckett, self-translation and the discourse of death". Marius Buning, Mitthijs Engelberts e Sjef Houppermans (orgs.) Samuel Beckett Today/Aujourd'hui 12 (special issue: Pastiches, Parodies and Other Imitations) p. 163-177.

NYKROG, Per (1984) "In the ruins of the past: reading Beckett intertextually" Comparative Literature 36 (4), 289-311.

PERLOFF, Marjorie (1996) Wittgenstein's ladder: poetic language and the strangeness of the ordinary. Chicago and London: The University of Chicago Press, 1996.

RABINOWITZ, Rubin (1995) "Samuel Beckett's revised aphorisms". Contemporary Literature 36 (2), 203-225.

(1985) "Samuel Beckett's figurative language". Contemporary Literature, $26(3), 317-330$.

SZAFRANIEC, Asja (2007) Beckett, Derrida, and the event of literature. Stanford: Stanford University Press.

WITTGENSTEIN, Ludwig. Lectures, Cambridge 1930-1932. Chicago: Chicago University Press, 1980.

WOLOSKY, Shira (1991) "The negative way negated: Samuel Beckett's texts for nothing". New Literary History 22 (1), 213-230.

(1989) "Samuel Beckett's figural evasions". Sanford Budick \& Wolfgang Iser (orgs.) Languages of the unsayable: the play of negativity in literature and literary theory. New York: Columbia University Press. 